\title{
Nomenclature for members of the expansin superfamily of genes and proteins
}

Hans Kende ${ }^{1, *}$, Kent J. Bradford ${ }^{2}$, David A. Brummell ${ }^{3}$, Hyung-Taeg Cho ${ }^{4}$, Daniel J. Cosgrove ${ }^{5}$, Andrew J. Fleming ${ }^{6}$, Chris Gehring ${ }^{7}$, Yi Lee ${ }^{8}$, Simon McQueen-Mason ${ }^{9}$, Jocelyn K.C. Rose $^{10}$ and Laurentius A.C.J. Voesenek ${ }^{11}$

${ }^{1}$ MSU-DOE Plant Research Laboratory, Michigan State University, East Lansing, MI 48824, USA (*author for correspondence; e-mail hkende@msu.edu); ${ }^{2}$ Seed Biotechnology Center, University of California, Davis CA 95616, USA, ${ }^{3}$ Crop and Food Research, Private Bag 11600, Palmerston North, 5301, New Zealand; ${ }^{4}$ School of Biosciences and Biotechnology, Chungnam National University, Daejeon 305-764, Republic of Korea; ${ }^{5}$ Department of Biology, 208 Mueller Laboratory, Pennsylvania State University, University Park, PA 16802, USA; ${ }^{6}$ Department of Animal and Plant Sciences, University of Sheffield, Western Bank, Sheffield S10 $2 T N, U K,{ }^{7}$ University of the Western Cape, Department of Biotechnology, Private Bag X17, Bellville 7535, South Africa; ${ }^{8}$ Department of Tobacco Science, Chungbuk National University, 48 Gaesin-dong Hungduk-ku, Chongju 361-763, Republic of Korea; ${ }^{9}$ Biology Department, University of York, PO Box 373, York, YO10 $5 Y W$, UK $;{ }^{10}$ Department of Plant Biology, Cornell University, Ithaca, NY 14853, USA; ${ }^{11}$ Plant Ecophysiology, Utrecht University, Sorbonnelaan 16, 3584 CA Utrecht, The Netherlands

Expansins were discovered as proteinaceous factors that have the capacity to induce extensibility and stress relaxation of plant cell walls in a $\mathrm{pH}-$ dependent manner (McQueen-Mason et al., 1992). Originally, two such proteins were isolated from cucumber cell walls. After the two genes encoding these expansins were cloned and sequenced (Shcherban et al., 1995), searches of the growing EST and genomic databases showed that expansins are encoded by large multigene families, and it was found that they occur in all land plants examined, ranging from bryophytes to angiosperms (for a review, see Li and Mc QueenMason, 2003). Evidence from work with transgenic plants indicates that endogenous expansins are not only involved in regulating growth (Cho and Cosgrove, 2000; Choi et al., 2003; Zenoni et al., 2004), but also developmental processes such as initiation of leaves (Pien et al., 2001), abscission (Cho and Cosgrove, 2000), and softening of tomato fruits (Brummell et al., 1999). After the initial discovery of the expansins, Cosgrove et al. (1997) found that group I allergens of grass pollen have regions of significant amino acid similarity to expansins and a high level of predicted secondary structure identity. Extracts of maize pollen and purified maize group I pollen allergen applied to grass cell walls in vitro were shown to have, indeed, expansin activity. Group I pollen allergens from other grass species likewise exhibited wall extension activity ( $\mathrm{Li}$ and Cosgrove, 2001). Transcripts encoding proteins similar to pollen allergens were also found in vegetative tissues, and it was suggested that these proteins also act as cell wall-loosening factors (Cosgrove $e t$ al., 1997).

The discovery of the pollen allergen-type expansins necessitated the introduction of a nomenclature that differentiated between the two expansin families. Expansins that are phylogenetically related to the originally discovered cucumber expansins were called $\alpha$-expansins, and expansins that are phylogenetically related to the group-1 grass pollen allergens were designated $\beta$-expansins (for reviews see Lee et al., 2001; Li and McQueenMason, 2003).

Further database searches revealed the existence of plant genes that encode proteins with distant homology to $\alpha$ - and $\beta$-expansins. These proteins have been called expansin-like and expansin-related (Lee et al., 2001), or were classified as $\beta 2$ - and $\beta 3$-expansins ( $\mathrm{Li}$ et al., 2002, Li and McQueen- Mason, 2003). Both $\alpha$ - and $\beta$-expansins consist of two domains: an N-terminal domain I 
that is distantly related to the catalytic domain of glycoside hydrolase family-45 (GH45) and a Cterminal domain II that is distantly related to group-2 grass pollen allergens (Cosgrove, 2000). Plants also have single-domain proteins that are distantly related to expansin domain I, and these have been named p12 proteins (Ceccardi et al., 1998), plant natriuretic peptides (Gehring and Irving, 2003) and $\gamma$-expansins ( $\mathrm{Li}$ et al., 2003). Moreover, grasses have a group of small proteins homologous to expansin domain II. These proteins, which have long been known as group-2/3 grass pollen allergens (Ansari et al., 1989), were recently designated $\delta$-expansins ( $\mathrm{Li}$ and McQueenMason 2003). Meanwhile, it also has become evident that the GH45-like domain is found in diverse proteins from many organisms other than plants, such as Dictyostelium (Li et al., 2002), mussels (Xu et al., 2001), fungi (Li et al., 2002; Saloheimo et al., 2002), nematodes (Qin et al., 2004), endosymbiotic protists in the termite hindgut (Ohtoko et al., 2000), and bacteria (Nembaware et al., 2004; D.J. Cosgrove and J. Sampedro Jimenez, unpublished data). This multitude of expansins and proteins with homologies to one or both expansins domains called for a unified and agreedupon nomenclature.

\section{General rules}

The expansin gene and protein nomenclature will follow the convention established for Arabidopsis (Meinke and Koornneef, 1997). Wild-type alleles are abbreviated with three italicized capital letters followed by a qualifying letter, for example, EXP A for a wild-type $\alpha$-expansin gene. Symbols for mutant alleles are written in lower-case and italicized letters $(\exp A)$. Different wild-type genes with the same gene symbol are assigned numbers (EXPA1, EXPA2, etc.). The numbering of genes will be in chronological order of their discovery. In cases of duplicate genes encoding identical proteins, the genes will be given the same number followed by a lower case letter ( $a, b, c$, and so on). Mutant alleles of a gene are assigned numbers connected with a hyphen to the gene symbol. Accordingly, mutant allele 1 of EXPA1 is designated expA1-1. The abbreviations for protein products of wild-type and mutant alleles correspond to the respective gene symbols but are written in non-italicized let- ters (EXPA1 or expA1-1). The species designation is given by the initial of the genus and species, such as AtEXPA1 for Arabidopsis thaliana $\alpha$-expansin gene 1. Potential conflicts arising from two species having the same initials should be resolved by adding one more differentiating letter to the genus or species abbreviation. Under any circumstance, the full gene name must be spelled out at first mention, for example, Arabidopsis thaliana EXPANSIN Al.

\section{Nomenclature of expansin and expansin-like genes and proteins}

The expansin and expansin-like designations are reserved for genes and their protein products that contain both domain I (the GH45-like domain) and domain II (similar to group-2 grass pollen allergens). Proteins having only one of these domains but not the other will not be classified as expansins.

The classification of expansin and expansin-like genes is based on their phylogenetic relationship. Phylogenetic evidence indicates that all plant expansin and expansin-like genes belong to the same superfamily of genes with a common ancestor (Lee et al., 2001; Li and McQueen-Mason, 2003). Figure 1 shows a phylogenetic tree of the expansin superfamily with representative sequences selected to illustrate the structure of the tree. Four protein families are currently recognized in plants and designated EXPA, EXPB, EXLA and EXLB (Table 1). Multiple members of the EXPA and EXPB families have been shown to possess in vitro expansin activity, namely the capacity to induce rapid extension or stress relaxation of isolated cell walls placed under uniaxial tension. The two expansin-like families, designated EXLA (EXPANSIN-LIKE A) and EXLB (EXPANSIN-LIKE B), possess both expansin domains, but their amino acid sequences are very divergent from EXPA and EXPB. No biological or biochemical function has yet been established for any member of the EXLA or EXLB families.

If any new gene families within the expansin superfamily of plants are discovered, they will be given the symbols $E X P C, E X P D$, or $E X L C, E X L D$, etc., as appropriate, following consultations with other workers in the expansin field via the expansin web site (see below). The symbol $E X L X$ may be 


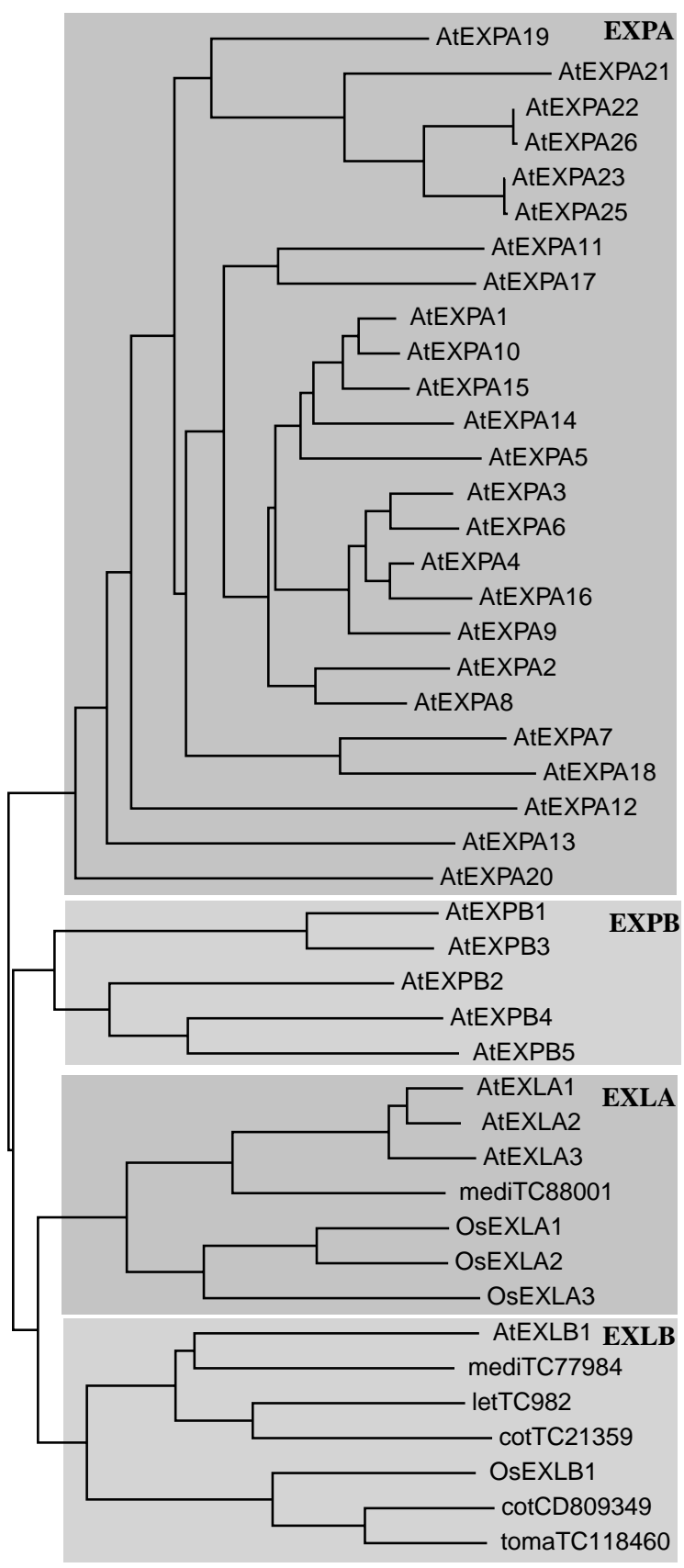

Figure 1. Phylogenetic tree of expansin protein sequences from Arabidopsis thaliana with additional EXLA and EXLB sequences from other species to balance the tree. This is a neighbor-joining tree constructed using the methods and sequences recommended at the website http://www.bio.psu.edu/ expansins/naming.htm. The additional EXLA and EXLB sequences are either from rice (Os) or from EST assemblies generated at www.tigr.org for cotton (cot), tomato (tom), alfalfa (medi) and lettuce (let). The TIGR EST assembly code is indicated in each name, e.g., TC88001.
Table 1. Revised names and symbols of expansin genes.

\begin{tabular}{|c|c|c|c|}
\hline $\begin{array}{l}\text { Original } \\
\text { name }\end{array}$ & $\begin{array}{l}\text { Former } \\
\text { symbol }^{\mathrm{a}}\end{array}$ & $\begin{array}{l}\text { New } \\
\text { symbol }\end{array}$ & New name \\
\hline$\alpha$-Expansin & $E X P$ or $E X P \alpha 1$ & EXPA & EXPANSIN A \\
\hline$\beta$-Expansin & $E X P B$ or $E X P \beta 1$ & $E X P B$ & EXPANSIN B \\
\hline Expansin-like & $E X P L$ or $E X P \beta 2$ & EXLA & EXPANSIN-LIKE A \\
\hline $\begin{array}{l}\text { Expansin- } \\
\text { related }\end{array}$ & $E X P R$ or $E X P \beta 3$ & $E X L B$ & EXPANSIN-LIKE B \\
\hline Various & $E X P$ or none & $E X L X$ & EXPANSIN-LIKE X \\
\hline
\end{tabular}

${ }^{a}$ As listed on the web site http://www.bio.psu.edu/expansins/ arabidopsis.htm and in Li et al. (2003).

used for genes that fulfill the following criteria: (i) they occur in non-plant organisms; (ii) their protein products have homologies to both expansin domains; and (iii) they do not fall within the established expansin gene families. The symbol EXLX does not represent a monophyletic gene family but is rather a temporary polyphyletic 'catch-all' group of expansin-like sequences that do not belong to the recognized expansin gene families. These genes will probably be renamed once the function of their protein products has been identified.

\section{Web site}

The web site http://www.bio.psu.edu/expansins/, currently maintained by Daniel Cosgrove, Pennsylvania State University, contains recent and archival information on expansins, including a summary of the nomenclature rules and a diagnostic tool to place newly identified expansins on the expansin phylogenetic tree. It lists the newly accepted symbols for all Arabidopsis and rice expansin genes, together with previously used symbols. This website is also the clearing house for questions concerning expansins, such as assignment of genus and species abbreviations when the initials are identical in two plant species.

\section{References}

Ansari, A.A., Shenbagamurthi, P. and Marsh, D.G. 1989. Complete primary structure of a Lolium perenne (perennial rye grass) pollen allergen, Lol p III: comparison with known Lol p I and II sequences. Biochemistry 28: 8665-8670.

Brummell, D.A., Harpster, M.H., Civello, P.M., Palys, J.M., Bennett, A.B. and Dunsmuir, P. 1999. Modification of expansin protein abundance in tomato fruit alters softening and cell wall polymer metabolism during ripening. Plant Cell 11: 2203-2216. 
Ceccardi, T.L., Barthe, G.A. and Derrick, K.S. 1998. A novel protein associated with citrus blight has sequence similarities to expansin. Plant Mol. Biol. 38: 775-783.

Cho, H.-T. and Cosgrove, D.J. 2000. Altered expression of expansin modulates leaf growth and pedicel abscission in Arabidopsis thaliana. Proc. Natl. Acad. Sci. USA 97: 97839788.

Choi, D., Lee Y., Cho, H.-T. and Kende, H. 2003. Regulation of expansin gene expression affects growth and development in transgenic rice plants. Plant Cell 15: 1386-1398.

Cosgrove, D.J. 2000. Loosening of plant cell walls by expansins. Nature 407: 321-326.

Cosgrove, D.J., Bedinger, P. and Durachko, D.M. 1997. Group I allergens of grass pollen as cell wall-loosening agents. Proc. Natl. Acad. Sci. USA 94: 6559-6564.

Gehring, C.A. and Irving, H.R. 2003. Natriuretic peptides-a class of heterologous molecules in plants. Int. J. Biochem. Cell Biol. 35: 1318-1322.

Lee, Y., Choi, D. and Kende, H. 2001. Expansins: everexpanding numbers and functions. Curr. Opin. Plant Biol. 4: $527-532$.

Li, L.-C. and Cosgrove, D.J. 2001. Grass group I pollen allergens ( $\beta$-expansins) lack proteinase activity and do not cause wall loosening via proteolysis. Eur. J. Biochem. 268: 4217-4226.

Li, Y., Darley, C.P., Ongaro, V., Fleming, A., Schipper, O., Baldauf, S.L. and McQueen-Mason, S.J. 2002. Plant expansins are a complex multigene family with an ancient evolutionary origin. Plant Physiol. 128: 854-864.

Li, Y. and McQueen-Mason, S. 2003. Expansins and cell growth. Curr. Opin. Plant Biol. 6: 603-610.

Meinke, D. and Koorrnneef, M. 1997. Community standards for Arabidopsis genetics. Plant J. 12: 247-253.

McQueen-Mason, S.J., Durachko, D.M. and Cosgrove, D.J. 1992. Two endogenous proteins that induce cell wall expansion in plants. Plant Cell 4: 1425-1433.
Nembaware, V., Seoighe, C., Sayed, M. and Gehring, C. 2004. A plant natriuretic peptide-like gene in the bacterial pathogen Xanthomonas axonopodis may induce hyperhydration in the plant host: a hypothesis of molecular mimicry. BMC Evol. Biol. 4: 10.

Pien, S., Wyrzykowska, J., McQueen-Mason, S.J., Smart, C. and Fleming, A.J. 2001. Local expression of expansin induces the entire process of leaf development and modifies leaf shape. Proc. Natl. Acad. Sci. USA 98: 11812-11817.

Qin, L., Kudla, U., Roze, E.H.A., Goverse, A., Popeijus, H., Nieuwland, H.O., Jones, J.T., Schots, A., Smant, G., Bakker, J. and Helder, J. 2004. A nematode expansin acting on plants. Nature 427: 30 .

Saloheimo, M., Paloheimo, M., Hakola, S., Pere, J., Swanson, B., Nyyssonen, E., Bhatia, A., Ward, M. and Penttila, M. 2002. Swollenin, a Trichoderma reesei protein with sequence similarity to the plant expansins, exhibits disruption activity on cellulosic materials. Eur. J. Biochem. 269: 4202-4211.

Shcherban, T.Y., Shi, J., Durachko, D.M., Guiltinan, M.J., McQueen-Mason, S.J., Shieh, M. and Cosgrove, D.J. 1995. Molecular cloning and sequence analysis of expansins - a highly conserved, multigene family of proteins that mediate cell wall extension in plants. Proc. Natl. Acad. Sci. USA 92: 9245-9249.

Xu, B., Janson, J.C. and Sellos, D. 2001. Cloning and sequencing of a molluscan endo- $\beta$-1,4-glucanase gene from the blue mussel, Mytilus edulis. Eur. J. Biochem. 268: 3718-3727.

Zenoni, S., Reale L., Tornielli, G.B., Lanfaloni, L., Porceddu, A., Ferrarini, A., Moretti, C., Zamboni, A., Speghini, A., Ferranti, F. and Pezzotti, M. 2004. Downregulation of the Petunia hybrida $\alpha$-expansin gene PhEXP1 reduces the amount of crystalline cellulose in cell walls and leads to phenotypic changes in petal limbs. Plant Cell 16: $295-308$ 